\title{
Pedagogical Efficacy of Experience-Based Learning (EBL) Strategies for Improving the Speaking Fluency of Upper-intermediate Male and Female Iranian EFL Students
}

\section{Ehsan Namaziandost ${ }^{1}$, Mehdi Nasri ${ }^{1}$, \& Fariba Rahimi Esfahani ${ }^{1 *}$}

* Correspondence:

Rahimi_fariba@yahoo.com

1. Department of English, Faculty of

Humanities, Shahrekord Branch,

Islamic Azad University, Shahrekord, Iran

Received: 23 December 2018

Revision: 21 March 2019

Accepted: 12 April 2019

Published online: 20 June 2019

\begin{abstract}
Learning from experience is a central physiological and theoretical idea in adult language learning which has become increasingly important in the field of second language acquisition (SLA) and is closely connected to task-based language teaching (TBLT). Accordingly, this study was designed to investigate the role of experience-based learning strategies in developing male and female upper-intermediate EFL learners' speaking fluency. To this end, from the target population of 300 language learners attending evening English classes at a language institute, a sample of 50 upper-intermediate participants were randomly chosen by administering an Oxford Placement Test (OPT). The average age of the selected students ranged between 17 and 25. An interview was utilized as a pre-test to determine participants' speaking fluency entry behavior. Subsequently, they were divided into two groups labeled as experimental and control groups. While the control group students received instruction through a traditional method without any focus on experience-based activities and strategies, those in the experimental group were exposed to interactive solutions verbally participating in class discussions during task-based classroom sessions in which they discussed their experiences in performing carefully prepared two-way tasks. The analysis of the data obtained from the post-test interview indicated that the participants in the experimental group outperformed those in the control group. Moreover, the results reflected that experience-based tasks considerably improved the learners' speaking fluency. Notably, the findings of the present study may have certain insightful pedagogical implications for language instructors and material developers.
\end{abstract}

Keywords: experience-based learning, speaking fluency, task-based instruction, two-way tasks 


\section{Introduction}

For decades, educational psychologists have studied the processes involved in language learning stating that all learning necessarily involves the intervening influence of the experiences that individuals bring into the learning task. Not surprisingly, learning from experience is a central philosophical and theoretical idea in the field of adult learning which has turned into a key element in experience-based learning (EBL) (Mollaei \& Rahnama, 2012). Through reflecting on their already acquired experiences and by evaluating and reconstructing them both individually and collectively, they can make their learning meaningful. The distinguishing feature of experience based learning or experimental learning is that learners' experiential repertoire plays a pivotal role in all aspects of teaching and learning. Evidently, such experiences are founded upon earlier events in the life of the learners, current life events, or those arising from the learner's participation in the activities designed and implemented by teachers acting as facilitators (Reinders, 2010).

Anderson, Boud, and Walker (1995) provide a list of criteria for experience-based learning language classes denoting that the main goal of experimental learning should primarily be creating an atmosphere which appears personally significant and meaningful to the students. Alternatively, by utilizing specific tasks, teachers personally engage learners in the learning process providing them with reflective thoughts and opportunities so that they can write or discuss their experiences throughout the process.

1. The whole person is involved, meaning not just their intellect but also their senses, their feelings, and their personalities.

2. Students should be recognized for prior learning they bring in to the process.

3. Teachers need to establish a since of trust, respect, openness, and concern for the well-being of the students.

Learners must also acquire the knowledge of how native speakers use the language in the context of the structured interpersonal exchange, in which many factors interact. Therefore, it is difficult for English as a foreign language (EFL) learners, especially adults, to speak the target language fluently and appropriately (Derakhshan, Nadi Khalil, \& Beheshti, 2016). EFL learners need explicit instruction in a speaking activity which as any language skill generally has to be learned and practiced. Also, they need to be fluent in their speaking. Schmidt's (1992) comprehensive review of the psychological mechanisms underlying second language fluency shows that it is not possible to account for developments in fluency simply through and increase in speed of processing. Substitutional increase in fluency also involves changes in the nature of the language knowledge.

The concept of "speaking fluency" is highly ignored throughout the traditional EFL instruction in Iran because there is very little time given to speaking activities for developing fluency in class and yet less curriculum and syllabus supporting or no systematic procedure for guiding the fluency development is provided for the students (Albino, 2017). In Iranian context, learning English is almost regarded as grammatical competence and the knowledge of vocabularies (Ghonsooly \& Hoseinpour, 2009; Namaziandost, Abdi Saray, \& Rahimi Esfahani, 2018). However, the traditional grammar-based learning model is now steadily replaced by the communicative language teaching approach to language learning, there is a need to work on students speaking fluency as well as accuracy (Yingjie, 2014). In EFL learning course in Ian, there are a lot of learners who attain knowledge in this field but they cannot speak fluently. Learners must acquire the knowledge of how native speakers used the language in the context of structure interpersonal exchange in which many factors interact. So, it is difficult for EFL learners to speak the target language fluently and appropriately (Meisel, 2011).

The process of learning from experience is called experience-based learning. Kurka (2012) believes that all learning necessarily involves experience of some sort, prior and/or current. The distinguishing feature of experience-based learning (or experiential learning) is that the experience of the learner occupies place in all considerations of teaching and learning. A key element of experience-based learning is that learners analyze their experience by reflecting and reconstructing it in order to draw meaning from it in the light prior experience.

\subsection{Statement of the Problem}

Considering the vital role of EBL, it has been observed that the majority of English majors at Iranian institutes encounter difficulties such as poor speaking skills, reluctance to participate in conversation, fear of committing errors, lack of confidence, and lack of English-speaking peers or social circles, which can help them to hone their speaking 
potential. In addition, most of the students are passive recipients of data as they take no initiative in participating in activities such as English club, seminars, language workshops which are intended for the enhancement of their speaking proficiency. Moreover, Philbrick, Maryott, and Magnuson (2017) intended to investigate how experiencebased learning approaches could be used to close the gaps between the skills that employers desire and the skills that students possess upon graduation. They concluded that there does not seem to be a clear and consistent understanding of the common discipline specific competencies that employers actually desire in undergraduate business students. In addition, Mollaei and Rahnama (2012) in a study indicated that how experiential education has come out, and how it has been adopted to the field of language education. Mollaei and Rahnama (2012) focused on identifying the concept of experiential learning, an experiential learning cycle, its principles and criteria, weaknesses, and strengths. They finally concluded that an obviously central component to theory-building is an attempt to understand how learning from experience occurs and what it is that is learned in the process. Another important point is that very few empirical researches have examined the pedagogical efficacy of experience-based learning (EBL) strategies for improving the speaking fluency. Therefore, the current research aims to fill this gap.

\subsection{Research Questions}

This study sought to answer the following questions:

Q1. To what extent, does experience-based learning strategies influence speaking fluency of male Iranian EFL learners?

Q2. Does explicit instruction of EBL strategies facilitate the speaking fluency of female Iranian EFL students?

\subsection{Research Hypotheses}

Based on the existing research questions of this study, the following hypothesis were formulated.

H01. Experience-based learning strategies do not influence on speaking fluency of male Iranian EFL learners.

H02. Explicit instruction of EBL strategies does not facilitate speaking of female Iranian EFL students.

\section{Review of the Literature}

Experience-based learning is not a very new construct. Niedermeyer (2014) believes that the history of experiencebased learning dates back to 85 years ago. He states that it was first introduced by john Dewey in the 1930s, who claims that all learning, in a very basic sense, is from experience. If we encounter a new situation, we relate it thus, emphasizes that experience is the foundation of, and the stimulus for, learning, and encourages learners to acknowledge and build on taken-for-granted processes which are often ignored in educational contexts. This approach which is totally different from the traditional knowledge-transmission approach to teaching, puts much emphasis on a participative, learner-centered, and constructivist approach (Niedermeyer, 2014).

Niedermeyer (2014) also believes that EBL cannot be limited to a group of techniques, methods, formulas or recipes which are introduced to students in the classroom. They believe that it is a set of features which are of paramount importance when implementing experience-based instruction. They list these characteristics as:

1) EBL appears to demand three factors and each is operating at some level. These are the involvement of the whole person-intellect, feelings, and senses.

2) Recognition and active use of all the learner's relevant life experiences and learning experiences. Where new learning can be related to personal experiences, the meaning thus derived is likely to be more effectively integrated into the learner's values and understanding.

3) Continued reflection upon earlier experiences in order to add and transform them into deeper understanding. This process lasts as long as the learner lives and has access to memory. The quality of reflective thought brought by the learner is of greater significance to the eventual learning outcomes than the nature of the experience itself. Learning is the process whereby knowledge is created through the transformation of experience (Kolb, 1984; Mollaei \& Rahnama, 2012). However, EBL varies in practice according to three possibilities while represent factors that may or may not be applicable in a particular instance.

4) Intentionality of design. Deliberately designed learning events are often referred to as structured activities and include simulations, games, role play, visualizations, focus group discussions, socio-drama, and hypotheticals. 
5) Facilitation. This is the involvement of some other persons (teachers, influenced by the degree of skill with which they operate). EBL often assumes relatively equal relationships between facilitator and learner, involves the possibility of negotiation, and gives the learner considerable control and autonomy.

6) Assessment of learning outcomes; and in the event assessment takes place much depends upon by what means, by whom, and for what purpose it is carried out. EBL is often as much concerned with the process as the outcomes of learning, and assessment procedures should accord with this. Assessment tasks congruent with EBL include individual or group projects, critical essays located in the leaner's own experience, reading logs, learning journals, negotiated learning contracts, peer assessment, and self- assessment. They might include a range of presentation modes other than writing, so as to enable the holism, context, and complexity of the learning to be evidenced.

Boud and walker (1990) state that one prominent characteristic in the literature related to experience-based learning is the central place of reflection. They formulated a model which suggests three phases of reflection related to experiential based learning activities. The first phase of reflection is preparation for experiential events, where it is important to focus on the learner, the learning milieu and the skills and strategies employed in reflection; next phase of reflection is reflection during an experiential activity, with its phases of noticing and intervening; and the third phase is reflection after the event, involving the individual in returning to experience, attending to feelings, and reevaluating the experience.

The word 'fluency' is generally applied in language teaching and 'fluent speaker' is mainly observed in language testing and assessment. This shows that the claims about fluency students and language learners generally make. Different scholars have suggested different things as indicators of speech fluency in their studies (Ghonsooly \& Hoseinpour, 2009). For instance, speech rate is regarded as in important predictor of speech fluency and is defined as the average number of syllables articulated per minute (Ejzenberg, 2000; Namaziandost, Abdi Saray, \& Rahimi Esfahani, 2018). It is interesting to know that there are a lot of other definitions for speaking fluency (Yingjie, 2014). According to Hartmann and Stork (1976), fluent speaker is a speaker who is capable of using the appropriate structures of a language at standard speed, which means natural speaking while the focus is on the delivery meaning rather than the form or structure of a language. In another definition of fluency, Fillmore (1979) allocates four characteristics to a fluent speaker. He states that a fluent speaker is someone who: a) has the ability to talk at length with few pauses; b) is able to produce the sentences coherently, reasoned, and semantically; c) can use appropriate expressions in a wide range of contexts; and d) is creative and imaginative in language use. Yet, there are other perceptions of fluency proposed by other scholars. Nation (1989) states that fluency has three dimensions: "the first one is the speed and flow of language production; secondly, the degree of control of language items i.e. pausing, rhythm, pronunciation, and stress; and the way of content interrupting is the last one." (p.58).

Repetition of an activity is a sure way of developing fluency with the particular items and sequences used in the activity. It is necessary to change the audience when designing repetition into meaning focused speaking activities so that the speaker does not change the spoken message to try to retain the interest of an audience that has already heard the message. The success of repetition activities largely depends on the repetition involving substantially the same message. In listener, each pair is replaced by a different listener for each repetition. In listening activities, the purpose for listening may need to change in order to keep the learner interned in the repeated message (Namaziandost, Sabzevari, Hashemifardnia, 2018).

Although fluency activities are aimed at the development of a skill, they inevitably affect knowledge of the language. The way that they affect this knowledge in turn relates to the development of fluency. We can distinguish three approaches to fluency development which can all usefully be part of language course (Mohamed Kassem, 2018). The first approach relies primarily on repetition and could be called "the well-beaten path approach" to fluency. This involves gaining repeated practice on the same material so that it can be performed fluency. The second approach to fluency relies on making many connection and associations with a known item. Rather than following one well beaten path, the learner can choose from many paths. This could be called "the richness approach" to fluency. This involves using the known item in a wide variety of contexts and situations. The third approach to fluency is the aim and result of the previous two approaches. This could be called "the well-ordered system approach." Fluency occurs because the learner is in control of the system of the language and can use a variety of efficient, well-connected, and well- practices paths to the wanted item (Namaziandost, Rahimi Esfahani, Nasri, \& Mirshekaran, 2018).

The following speaking fluency activities make use of repetition and rehearsal and are discreet activities. It is also possible for theme- based work over several days to develop in to fluency development opportunities. The 4/3/2 
technique combines the features of focus on the message, quantity of production (the speakers speak for a total of nine minutes), learner control over the topic and language used, repetition, and time pressure to reach a high rate of production through the decreasing amount of time available for each delivery. The best recording is a useful fluency activity involving a tape or digital recorder or the language laboratory. The learner speaks on to the tape talking about a previous experience or describing a picture or set of pictures. The learner listens to the recording nothing any points where improvement could be made. Then the learner re-records the talk. This continues until the learner is happy with the recording. This technique can involve planning and encourages repetition of the setting of a quality-based goal (Yingjie, 2014).

Boud and Walker (1992) provided a way of conceptualizing experience-based learning which considers the personal foundation of experience of learners, their intent and their interaction with a learning milieu. They concluded that by approaching the experience as an interaction between the learner and the learning milieu, we have focused attention on understanding what the learner brings to the situation, and how it is the learner's involvement with the event that constitutes the learning experience. In another study, Schmidt (1992) concluded that comprehensive review of the psychological mechanisms underlying second language fluency shows that it is not possible to account for developments in fluency simply through increase.

Mollaei and Rahnama (2012) offered a historical background of how experiential education has emerged, and how it has been adopted to the field of language education. They focused on identifying the concept of experiential learning, an experiential learning cycle, its principles and criteria, weaknesses, and strengths. They concluded that EBL is not grounded in a systematic theory or model of how we learn from experience and what it is that is learned. The conceptual meaning of the idea of experience-based learning remains elusive and many practitioners are not clear on what specific approaches to use to facilitate this form of learning or when to use them. As a result, for participants in adult education programs, experience-based learning is often more a promise than a reality.

Salem and Al Dyiar (2014) aimed at investigating the relationship between speaking anxiety and oral fluency of Arab intermediate school students. It also investigates the differences between male and female students in speaking anxiety profile and their oral fluency performance. The sample of the study consists of 121 students in intermediate school in the state of Kuwait (68 males and 53 females). The mean age of the sample is 9.74 years and standard deviation is 1.46 years. The descriptive research design was used. Results of the study showed that there is positive relation between student speaking anxiety and their performance in oral performance skills of male students and the total sample of the study. It is also found that no relations were found between female students speaking anxiety and their oral fluency performance. Findings indicated that there were statistically significant differences between male and female students in oral fluency in favor of male students. Whereas, no statistically significant differences were found between male and female students in their speaking anxiety.

Albino (2017) attempted to assess how EFL learners improved their speaking fluency in a task-based language teaching (TBLT) approach used with ninth-grade learners at PUNIV-Cazenga, a high school in Luanda. In a case study design that used picture-description tasks, learners' speeches were audio recorded before and after the teaching, in which recasts and prompts were utilized as feedback tools for 8 weeks. The findings indicated that learners improved in terms of their speaking fluency by maximizing their speed of speech production, increasing grammatical accuracy, elaborating on their utterances, and developing interactional language. Furthermore, learners' opinions on being taught with the TBLT approach were sought, and the findings indicated that the learners felt encouraged to speak, believed in their potentials to use the target language, expanded their vocabulary, and recognized the relevance of the TBLT approach.

Mohamed Kassem (2018) used a Hybrid Problem-Based Learning (HPBL) approach for teaching a speaking course to the first-year students of the English Department at Prince Sattam Bin Abdulaziz University, Saudi Arabia. Results revealed that the HPBL approach has a positive effect on improving the students' speaking proficiency, students' motivation significantly increased and, eventually, students tended to be more self-directed and independent. In another study, Namaziandost, Abdi Saray, and Rahimi Esfahani (2018) investigated the effect of writing practice on improving speaking skill among pre-intermediate EFL learners. To this end, the researchers selected two preintermediate intact classes and randomly assigned them in two equal groups; one experimental group ( $\mathrm{n}=25)$ and one control group $(n=25)$. Data were analyzed by Paired and Independent Samples t-test. The results indicated that not only writing proficiency but also the speaking proficiency of the experimental group had significantly improved. The findings revealed that the experimental group significantly outperformed the control group $(\mathrm{p}<.05)$ on the post-test. 


\section{Methodology}

\subsection{Design of the Study}

This study made use of quasi-experimental design to investigate whether adopting experience-based strategies have any significant effect on intermediate students' speaking fluency or not. The control group students were instructed in traditional method without any focus on experience-based activities and strategies. However, the experimental group students' participation included interactive solutions and answers, asking questions and verbally participating in class discussions during the task-based classroom sessions in which they discussed their experiences in the form of tasks. The teachers, as Teaching English as a Foreign Language (TEFL) specialists, were also trained in task-based instruction and activities.

\subsection{Participants}

This study was conducted in two private language institutes in Isfahan, Iran. Kaj institute from which male participants were recruited and Farasat institutes from which female participants were recruited. Four classes (Two classes as experimental and 2 classes as control group) were selected. Fifty upper-intermediate learners were selected among 300 participants through administering an oxford placement test (OPT). Half of the participants (those in Kaj institute) were male and half of them (those in Farasat institute) were female. In this study, 25 participants were assigned to the experimental group and 25 participants were assigned to the control group. In other words, one class in Kaj and one class in Farasat institute (total of 25 participants) were assigned to experimental group and the two remaining classes were assigned to control group. Therefore, in this study, there were two control group and two experimental groups. All the subjects were native speakers on Persian and learners of English as a foreign language. These students had an average age, range from 17-25 years old. The summary of participants' information is shown in Table 1.

Table 1. Participants' information

\begin{tabular}{ccc}
\hline Gender & Groups & Number \\
\hline Male & Experimental group & 13 \\
\cline { 2 - 3 } & Control group & 12 \\
\hline Female & Experimental group & 12 \\
& Control group & 13 \\
\hline
\end{tabular}

\subsection{Instruments}

Three main instruments were used in this study. 1) OQPT: The first instrument which was employed in the present study to homogenize the participants was the OQPT. It helped the researchers to have a greater understanding of what level (i.e., elementary, pre-intermediate, and intermediate) their participants were at. According to this test, the learners whose scores were between 41 to 50 (out of 60) were considered as the pre-intermediate learners. 2) Pre-test: The second instrument was an interview as pre-test. The pretest lasted about 65 minutes which aimed to check the participants' speaking fluency. After the pre-test conducted, the treatment was applied to both groups. The validity of the pre-test was confirmed by 3 English University professors who taught English for more than 10 years. Moreover, the reliability of the pre-test was calculated through Cronbach alpha formula and it was ( $\mathrm{r}=.899)$. 3) Post-test: After the treatment ended, another interview was run as post-test. Like pre-test, the post-test lasted about 65 minutes. The post-test aimed to check the effect of treatment on participants' speaking fluency. The validity of the post-test was also checked by those university professors who validated the pre-test and its reliability was computed through Cronbach alpha formula and it was $(\mathrm{r}=.936)$.

\subsection{Procedure}

The following steps were followed to conduct this study. 1) Administering English proficiency test to check the participants' English proficiency level. 2) Carrying out the pre-test to check the participants' speaking fluency before treatment. 3) Administering the treatment: The most common tasks which were applied for experimental group 
participants were a set of two-way tasks. Three types of two-way exchange tasks that elicited collaborative interaction were chosen for the current study. It needs to be added that all the topics for the tasks were in a way to be related to their previous experience. The experimental group participants took part in activities where all the language items were within their previous experience. Information gap (jigsaw) and goal-oriented (spot-the-differences) activities are closed tasks with one possible outcome. These two-way exchanges promote negotiation of meaning and form (Skehan, 2003). For instance, one of the goal-oriented activities was for the participants to work together to identify 15 differences between their houses. It is likely that specific lexical items or grammar points would be required to achieve mutual comprehension. In contrast, open-ended questions allow free responses that may not necessarily require precise information to complete the task. The topics for the tasks were chosen in a way to involve both spoken and written. Learners work with largely familiar topics and types of discourse making use of known vocabulary and structures. According to Brumfit (1985), these kinds of activities are called "experience" tasks because the knowledge required to do the activity is already well within learners' experience. 4) Running the post-test at the end of the study to check if the treatment had any effect on learners' speaking fluency.

\subsection{Data Collection}

To conduct the present study, the researchers attended the above-mentioned institutes and administrated the OQPT to 300 students to determine their level of English proficiency. The researchers selected 50 upper-intermediate students and randomly divided them into two groups, namely; one experimental group and one control group. After that the researchers started the main study which included the following stages: The first session of the study started with conducting the interviews (pre-test) to both experimental and control group participants. The main length of each interview was 65 minutes. The average number of words per minute for each participant was recorded. After that, the researchers carried out the treatment sessions. At the end of educational term, one week before the post-test, both groups stopped receiving instruction. Then, both groups again came together to take the post interview, which was similar to pre-test. Through comparison of the pre and post words per minute for each participant, the effects of experience-based instruction on students' fluency of speech were measured. When the data were gathered through pre-test and post-test, it was time to carry out data analysis.

\subsection{Data Analysis}

The participants' mean frequency of words per minute in their interviews, both for pre-test and post-test, were conducted and entered into SPSS data file. The data file was inspected visually for missing data or anomalous entries. Reversed scores were computed and data were independently checked for entry errors. Descriptive analysis was then conducted to measure the mean, standard deviation, and normality of distribution for the scores of pre-test and posttest. This information was necessary for deciding what variables could be concluded with confidence in the primary analysis addressing the study's research question. To analyze the fluency test results, the researchers launched a Smirnov-Kolmogorov to check the homogeneity of the participants of both groups. Since the results were satisfactory, the researchers started to compare mean of both group test results, using T-test.

\section{Results}

The first null hypothesis was concerned with the effects of experience-based learning on male intermediate students' speaking fluency. Two independent t- test procedures were used to compare the fluency test results of the two groups of male learner's traditional based instruction. Descriptive statistics and the comparison of fluency test results in pretest for the two groups are shown in Table 2.

Table 2. Descriptive statistics for pre-test speaking fluency of male control and experimental groups (Words per minute)

\begin{tabular}{cccccc}
\hline Group & Variable & $\mathrm{N}$ & Mean & Std. deviation & Std. error mean \\
\hline Control group & Traditional & 12 & 71.34 & 0.25028 & 0.6070 \\
\cline { 2 - 5 } Experimental group & Experience based & 13 & 68.66 & 0.15269 & 0.3703
\end{tabular}


As it is observed in Table 2, there was a difference between the two groups' average word per minute (WPM). While the students in control group uttered 71.34 WPM, the students in experimental group uttered 68.66 WPM in pre-test fluency test. To check the significance of difference between the two groups, the results of T-test indicated that, as we expected, the speaking fluency between the two groups in the pre-test was not significant $(\mathrm{p}>0.5)($ Table 3$)$.

Table 3. Independent sample T-test for significance of pre-test speaking fluency difference among male participants

\begin{tabular}{cccccc}
\hline Variable & F & Sig. & T & Df & Sig. (2-tailed) \\
\hline Speaking fluency & 1.962 & 0.171 & 0.298 & 12 & 0.768 \\
\hline$* *$ : significant at 0.01. & & & &
\end{tabular}

As Table 3 indicates, Levene test result is higher than 0.05, which indicates that the two groups are homogeneous. Since Levene test t-test result was not equal to 0 , it is needed to have the equal variance assumed (the first row) for the Sig. (2-tailed), which equals 0.768. As the t-test result indicates, the two groups were not significantly different before the treatment. However, as the post-test result indicated, the speaking fluency was changed after the treatment. Descriptive statistics for post-test speaking fluency difference of both groups are indicated in Table 4.

Table 4. Descriptive statistics for post-test speaking fluency of male control and experimental groups (WPM)

\begin{tabular}{cccccc}
\hline Group & Variable & $N$ & Mean & Std. deviation & Std. error mean \\
\hline Control group & Traditional & 12 & 73.1453 & 0.18197 & 0.04413 \\
\cline { 2 - 5 } Experimental group & Experience based & 13 & 76.7276 & 0.26350 & 0.06391 \\
\hline
\end{tabular}

As Table 4 shows, the speaking fluency of male participants in both groups has raised. The control group's average WPM was 73.1 while experimental group's average WPM was 76.72. So, both group participants had developed their speaking fluencies. However, this needs to be statistically checked to see if this difference between the two groups is statistically significant or not. T-test results of post treatment speaking fluency test indicates that the fluency of experimental group has been changed by treatment ( $\mathrm{t}$-test for $\mathrm{p}<0.05$ is significant). T-test results have been shown in Table 5. T-test results for $\mathrm{p}<0.05$ equaled 0.00 .

Table 5. Independent sample t-test results for posttest speaking fluency of male participants

\begin{tabular}{cccccc}
\hline Variable & F & Sig. & T & Df & Sig. (2-tailed) \\
\hline Speaking fluency & 1.37 & 0.250 & -7.498 & 12 & $0.00^{* *}$ \\
\hline
\end{tabular}

** Significant at 0.01 .

Therefore, based on the results of data analysis reported above, the first null hypothesis, predicting an insignificant role of experience-based instruction on male upper-intermediate learner's speaking fluency, was rejected. The first null hypothesis was concerned with the effects of experience-based learning on female intermediate student's speaking fluency. Two independent t-test procedures were used to compare the fluency test results of the two groups of female participants (control group and experimental group), before and after experienced-based and traditional-based instruction. Descriptive statistics and the comparison of fluency text results in pre-test for the two groups are shown in Table 6. 
Table 6. Descriptive statistics for pre-test speaking fluency of female control and experimental groups (Words per minute)

\begin{tabular}{cccccc}
\hline Group & Variable & $N$ & Mean & Std. deviation & Std. error mean \\
\hline Control group & Traditional & 13 & 70.58 & 0.22014 & 0.4045 \\
Experimental group & Experience based & 12 & 69.61 & 0.23545 & 0.02561 \\
\hline
\end{tabular}

As it is observed in Table 6, there was a difference between the two group's averages Word per Minute (WPM). While the students in control group uttered 70.58 WPM, the students in experimental group uttered 69.61 WPM in pre-test fluency test. To check the significance of difference between the two groups, after the calculation of the means for each item in experimental and control group, the means were compared. The results of t-test indicated that, as we expected, the speaking fluency between the two groups in the pre-test was not significant (p>0.5) (Table 7).

Table 7. Independent sample T-test for significance of pre-test speaking fluency difference among female participants

\begin{tabular}{cccccc}
\hline Variable & F & Sig. & T & Df & Sig. (2-tailed) \\
\hline Speaking fluency score & 1.578 & 0.211 & 0.223 & 12 & 0.657 \\
\hline
\end{tabular}

As Table 7 indicates, Levene test result is higher than $0.05,(=.211)$ which by itself indicates that the two groups are homogeneous. Since Levene test t-test result was not equal to 0 (zero), it is needed to have the equal variance assumed (the first row) for the Sig. (2-tailed), which equals 0.657. As the t-test results indicates, the two groups were not significantly different before the treatment. However, as the post-test result indicated, the speaking fluency of female participants was changed after the treatment. Descriptive statistics for post-test speaking fluency difference of both groups are indicated in Table 8.

Table 8. Descriptive statistics for post-test speaking fluency of female control and experimental groups (WPM)

\begin{tabular}{cccccc}
\hline Group & Variable & $N$ & Mean & Std. deviation & Std. error mean \\
\hline Control group & Traditional & 13 & 72.234 & 0.254 & 0.3154 \\
\cline { 2 - 5 } Experimental group & Experience based & 12 & 77.126 & 0.5142 & 0.0544 \\
\hline
\end{tabular}

As Table 8 shows, the speaking fluency of female participants in both groups has raised. The control group's average WPM was 72.23 while experimental group's average WPM was 77.12 so, both group participants had developed their speaking fluencies. However, this needs to be statistically checked to see if this treatment speaking fluency test indicates that the fluency of experimental group has been changed by treatment ( $\mathrm{t}$-test for $\mathrm{p}<0.05$ is significant). $\mathrm{T}$ test results have been shown in Table 9. T- Test results for $\mathrm{p}<0.05$ equaled 0.021 .

Table 9. Independent t-test results for post-test speaking fluency of female participants

\begin{tabular}{cccccc}
\hline Variable & F & Sig. & T & Df & Sig. (2-tailed) \\
\hline Speaking fluency & 1.22 & 0.191 & -4.235 & 12 & $0.021 * *$
\end{tabular}

Therefore, based on the results of data analysis reported above, the second null hypothesis, predicting an insignificant role of experience-based instruction of female upper-intermediate learners speaking fluency, was rejected. 


\section{Discussion}

Teaching involves many elements; however, instruction is central to the teaching process, and it is essential for teachers to refine their instructional skills continually (Namaziandost, Abdi Saray, \& Rahimi Esfahani, 2018). This is arduous for experienced teachers and a great challenge for novices. Action research has particular relevance for the personal development of novice teachers. Used within the context of communities of practice, learning can be thus shared to help shared development of teaching practice. The first year of teaching for many is a period of frantic activity involving many personal and professional adjustments aimed at classroom survival through coping strategies (Doyle, 1985). Teachers develop their educational behaviors in an orderly manner that forms a predictable pattern as they gain experience (Namaziandost, Abdi Saray, \& Rahimi Esfahani, 2018). Considering the aforementioned results, it is now possible to consider the two research questions in light of empirical evidence and compare or contrast the present study in this phase with the similar ones to make the results more meaningful. Regarding the research questions of this study, analysis of the data revealed the significant role of experience-based instruction in upper-intermediate male and female student's fluency. This means that experience-based instruction influences speaking fluency of male and female upper- intermediate learners of English.

The findings of this study, though indirectly, are supported by Niedermeyer (2014) who claims that fluency is raised when language learners draw on meaning focused activity and perform it with speed and ease without holding up the flow of talk. On the other hand, Boud and Walker (2000) claim that as a vital criterion for calling a course experiencebased instruction, the goal of experience-based instruction should involve something personally significant or meaningful to the students. Since, the concept of meaning is common in Mohamed Kassem's (2018) study, it would seem to be reasonable to claim that experience-based learning and speaking fluency are related constructs. A key element of experience-based learning is that learners analyze their experience by reflecting and reconstructing it in order to draw meaning from it in the light prior experience, it could be claimed that the element of "focus on meaning" was the central factor which made the participants more fluent language learners after they were provided with experience-based activities. Experiential learning encourages personal input, initiative, and self-direction in the learning process. Activities begin with accessing the specific past experiences of students, and then building on these experiences to construct a framework for learning unique to the requirements and learning style of each student. In practice, experience-based, project-based, and task-based learning become experiential when elements of reflection, support, and transfer are added to the basic experience, transforming a simple activity into an opportunity for learning.

Mollaei and Rahnama' (2012) statement also provides support for the findings of this study. He believes that fluency develops when the learners perform activities in which all the language items are within their previous experience. In such a condition, the learners deal with very familiar topics and types of discourse making use of known vocabulary and structures. From Mollaei and Rahnama's (2012) statements, it could be inferred that fluency is previous experience of learners that is the central component of experience-based learning. It could be claimed that fluency is improved with a focus on experience-based strategies. Implementing EBL in formal education is generally associated with negotiated curricula, and leads to increases in student self-concept, and a greater awareness of the implicit ethical considerations in teaching and learning. EBL has been embraced at many levels in Iranian higher education, from whole programs to sections of courses through the use of the practicum and internships in university courses and professional bodies for admission purposes (engineering, teaching, chartered accountancy, nursing, law, medicine). Many professional bodies are collaborating with educational providers to design relevant courses which take account of the experience of their constituency and thus are more cost-efficient.

Regarding the role of gender in developing fluency through experience-based learning, Yingjie's (2014) comprehensive review of the psychological mechanisms underlying second language fluency shows that it is not possible to account for developments in fluency simply through an increase in speed of processing. Then according to the findings of this study, it could be claimed that experience-based learning develops both male and female upperintermediate students' speed of processing. This claim is made because based on the results, both male and female participants developed their speaking fluency after they received experience-based instruction. The result of this study is in line with Mohamed Kassem (2018) who used a HPBL approach for teaching a speaking course to the first-year students. The HPBL approach has been proved to be an effective model for teaching language skills; however, the existing literature still lacks an actual action plan or a methodology to introduce this approach as a pedagogical remedy for motivating EFL students and improving their speaking proficiency. The study addressed this gap by recommending 
the use of HPBL approach in EFL speaking classes. The study used a pre-post speaking proficiency test, a student's motivation questionnaire, interviews, and observation sheets as data collection tools. Results revealed that the HPBL approach has a positive effect on improving the students' speaking proficiency, students' motivation significantly increased and, eventually, students tended to be more self-directed and independent. Instructors also applauded to use HPBL approach but recommended adapting the curriculum and the teaching strategies to support this approach.

Moreover, the findings of this study support those of Albino (2017) who attempted to assess how EFL learners improved their speaking fluency in a TBLT approach used with ninth-grade learners at PUNIV-Cazenga, a high school in Luanda. In a case study design that used picture-description tasks, learners' speeches were audio recorded before and after the teaching, in which recasts and prompts were utilized as feedback tools for 8 weeks. The findings indicated that learners improved in terms of their speaking fluency by maximizing their speed of speech production, increasing grammatical accuracy, elaborating on their utterances, and developing interactional language. Furthermore, learners' ideas on being taught with the TBLT approach were sought and the results revealed that the learners motivated to speak, expanded their vocabulary, and recognized the importance of the TBLT approach.

The distinguishing feature of experience-based learning is that the experience of the learner occupies central place in all considerations of teaching and learning. This experience may involve earlier events in the life of the learner, current life events, or those arising from the learners' participation in activities implemented by teachers and facilitators. All learning necessarily involves experience of some sort, prior and/or current. However, scrutiny of many contemporary teaching and training practices might lead one to think otherwise. Much of the impetus for EBL has been a reaction against an approach to learning which is overly didactic, teacher controlled and involving a discipline-constrained transmission of knowledge. It supports a more participative, learner-centred approach, which places an emphasis on direct engagement, rich learning events, and the construction of meaning by learners. EBL is of particular interest to adult educators because it encompasses formal learning, informal learning, non-formal learning, lifelong learning, incidental learning, and workplace learning.

Dewey (2014) stated that not all experiences are genuinely or equally educative. Current thinking might amplify this and suggest that the learning is likely to be recognized and applied only in so far as the learner actively reflects upon the experience. The results of this study are contrary to Salem and Al Dyiar (2014) who investigated the relationship between speaking anxiety and oral fluency of Arab intermediate school students. It also investigates the differences between male and female students in speaking anxiety profile and their oral fluency performance. Salem and Al Dyiar's (2014) findings indicated that there were statistically significant differences between male and female students in oral fluency in favor of male students. Whereas no statistically significant differences were found between male and female students in their speaking anxiety.

\section{Conclusion}

Knowledge is social as well as individual. A body of knowledge can develop through a process of communal involvement. Therefore, the present study tried to investigate the role of experience-based instruction in developing speaking skills of upper-intermediate students in general and developing speaking fluency in particular. As mentioned earlier in this paper, experiential learning is participative, interactive, and applied. It allows contact with the environment, and exposure to processes that are highly variable and uncertain. It involves the whole-person; learning takes place on the affective and behavioral dimensions as well as on the cognitive dimension. The experience needs to be structured to some degree; relevant learning objectives need to be specified and the conduct of the experience needs to be monitored. Students need to evaluate the experience in light of theory and in light of their own feelings. In this study, the control group was taught task-based approach whose topics were not related to previous experience of the participants and the experimental group received task-based instruction with a focus on learner's previous experience. After comparing the mean word frequency of pre-test and post-test results, it was revealed that participants speaking fluency has been significantly improved as a result of experience-based instruction.

Putting it in another way, after the experience-based instruction program, the upper-intermediate students were more fluent speakers of English. Furthermore, based on the findings, there is no difference between male and female students in developing their speaking fluency through experience-based instruction. The findings seem to be indication that the rate of developing speaking fluency among male and female language learners is the same. Since using English language for better communication with female participants are not different in developing skills related to communication with other people. The researchers concluded that through experience, learners are able to construct firsthand a sense of understanding of the events going on around them. Educators have begun to harness the power of 
experience in study abroad courses, field studies, role plays, and numerous computer-based interventions. The future could bring even more applications of this theory, a possibility as exciting for the learner as much as it is the facilitator. Most often, however, a learner needs some amount of freedom to develop experience-based understanding; likewise, in most educational settings, learners need some degree of guidance as well.

Another important point is that experiential learning is not totally new. But it suggests a renewed look at the way teaching and learning get organized in our classrooms. It suggests that the learner must occupy the center stages of classroom activity and not the teacher. The approaches which engage students in interdisciplinary exploration, collaborative activity and field-based opportunities for experiential learning, reflection and self-examination are used more and more by the teachers. The rise of participant's fluency can also be justified by positive factors in them when they speak about their previous experience which is proposed that to develop student's fluency of speaking, implementing affective variable could be promising. Then it could be concluded that linking the tasks to student's previous experience may act as an effective strategy.

Moreover, anxiety is the most challenging affective factor that the language learners face. This anxiety may negatively influence their accuracy and fluency. However, the researchers noticed that male and female students differ in the degree of anxiety they feel when they speak. This means that, in the context of our study, male and female participants did not differ in the degree of anxiety they feel. Last but not least, all teachers whether novice or expert should question and explore their teaching methods to identify ways of improving these within their local communities of practice. Ultimately teaching results in imparting quality teaching to students to enable to deliver high quality care. In keeping with the general impetus of contemporary teaching practice, teaching needs to occur within the context of departmental and individual reflection on practice to ensure continuous knowledge development and skill improvement.

\section{References}

Albino, G. (2017). Improving speaking fluency in a task-based language teaching approach: The case of EFL learners at PUNIV-Cazenga. SAGE Open, 7(2), 1-11. https://doi.org/10.1177/2158244017691

Andersen, L., Boud, D., \& Cohen, R. (1995). Experience-based learning. In G. Foley (Ed.), Understanding adult education and training (pp. 225-239). Sydney: Allen \& Unwin.

Boud, D., \& Walker, D. (1990). Making the most of experience. Studies in Continuing Education, 12(2), 61-80. https://www.tandfonline.com/doi/abs/10.1080/0158037900120201

Boud, D., \& Walker, D. (1992). In the midst of experience: Developing a model to aid learners and facilitators. InJ.Mulligan \& C. Griffin (Eds.), Empowerment through experiential learning: Explorations of good practice (pp.163-169). London: Kogan Page.

Brumfit, C. (1985). Communicative methodology in language teaching. Cambridge: Cambridge University Press.

Candling, C. N. (1987). Towards task-based learning. In C. N. Candling, \& D. Murphy (Eds.), language learning tasks. Englewood Cliffs, NJ: prentice hall.

Derakhshan, A., Nadi Khalil, A., \& Beheshti, F. (2016). Developing EFL learner's speaking ability, accuracy and fluency. English Language and Literature Studies, 6(2), 177-186. http://dx.doi.org/10.5539/ells.v6n2p177

Dewey, J. (2014). Experience and education. New York: Collier Books.

Ejzenberg, R. (2000). The juggling act of oral fluency: a psycho- sociolinguistic metaphor. In H. Riggenbach (Eds.), perspectives on fluency (pp. 287-314). Michigan: The University of Michigan Press.

Fillmore, C. J. (1989). On fluency. In D. Kempler \& W. S. Y. Wang (Eds.), individual differences in language ability and language behavior (pp. 85-102). New York: Academic Press.

Ghonsooly, B., \& Hoseinpour, A. (2009). The effect of concept mapping on EFL speaking fluency. IJAL, 12(1), 87115. URL: http://ijal.khu.ac.ir/article-1-60-en.html

Hartmann, R. R. K., \& Stork, F. C. (1976). Dictionary of language and linguistics. New York: Wiley.

Kolb, D. A. (1984). Experiential learning: Experience as the source of learning and development. New Jersey: Prentice-Hall. 
Kurka, V. J. (2012). Recognizing culture in experiential education: An analysis and framework for practitioners. Master's Capstone Projects. 20. Retrieved from https://scholarworks.umass.edu/cie_capstones/20

Meisel, J. M. (2011). Bilingual language acquisition and theories of diachronic change: Bilingualism as cause and effect of grammatical change. Bilingualism: Language and Cognition, 14(2), 121-145. doi: $10.1017 /$ S1366728910000143

Mohamed Kassem, M. A. (2018). Improving EFL students' speaking proficiency and motivation: A hybrid problembased learning approach. Theory and Practice in Language Studies, 8(7), 848-859. doi: http://dx.doi.org/10.17507/tpls.0807.17

Mollaei, F., \& Rahnama, H. (2012). Experiential education contributing to language learning. International Journal of Humanities and Social www.ijhssnet.com/journals/Vol_2_No 21_November_2012/31.pdf

Namaziandost, E., Abdi Saray, A., \& Rahimi Esfahani, F. (2018). The effect of writing practice on improving speaking skill among pre-intermediate EFL learners. Theory and Practice in Language Studies, 8(1), 1690-1697. doi: http://dx.doi.org/10.17507/tpls.0812.16

Namaziandost, E., Rahimi Esfahani, F., Nasri, M., \& Mirshekaran, R. (2018). The effect of gallery walk technique on pre-intermediate EFL learners' speaking skill. Language Teaching Research Quarterly, 8, 1-15.

Namaziandost, E., Sabzevari, A., \& Hashemifardnia, A. (2018). The effect of cultural materials on listening comprehension among Iranian upper-intermediate EFL learners: In reference to gender. Cogent Education, 5(1), 1-17. https://doi.org/10.1080/2331186X.2018.1560601

Nation, P. (1989). Improving speaking fluency. System, 17(3), 377-384. doi: 10.1016/0346-251X(89)90010-9

Niedermeyer, W. J. (2014). Revolutionary education: A modern synthesis of John Dewey's evolutionary philosophy and educational theory. Doctor of Education (EdD). Paper 28. http://digitalcommons.georgefox.edu/edd/28

Philbrick, K. A., Maryott, K. M., \& Magnuson, R. A. (2017). Using experience-based learning to enhance student success: Step 1-Exploratory research to identify discipline-specific competencies. Developments in Business $\begin{array}{llll}\text { Simulation and } & \text { Experiential }\end{array}$ https://journals.tdl.org/absel/index.php/absel/article/view/3077.

Reinders, H. (2010). Towards a classroom pedagogy for learner autonomy: A framework of independent language learning skills. Australian Journal of Teacher Education, 35(5), 40-55. http://dx.doi.org/10.14221/ajte.2010v35n5.4

Salem, A. A. M. M., \& Mosaad A. A. D. (2014). The relationship between speaking anxiety and oral fluency of special education Arab learners of English. Asian Social Science 10(12), 170-176. doi:10.5539/ass.v10n12p170

Schmidt, R. (1992.) Psychological mechanisms underlying second language fluency. Studies in Second Language Acquisition, 14(4), 357-385. https://doi.org/10.1017/S0272263100011189

Skehan, P. (2003). Task-based instruction. Language Teaching, 36(1), 1-14. doi: 10.1017/S026144480200188 8X

Yingjie, Y. (2014). The development of speaking fluency: The 4/3/2 technique for the EFL learners in China. International Journal of Research Studies in Language Learning, 3(4), 55-70. doi: 10.5861/ijrsll.2013.624 